\title{
Patient-Reported Outcomes in Gastroenterology: Clinical and Research Applications
}

\author{
Brennan M R Spiegel \\ Department of Gastroenterology, VA Greater Los Angeles Healthcare System; Division of Digestive Diseases, David Geffen School of Medicine \\ at UCLA; Department of Health Services, UCLA School of Public Health; and UCLA/VA Center for Outcomes Research and Education, Los \\ Angeles, California, USA
}

\begin{abstract}
Patient-generated reports, also known as Patient-Reported Outcomes (PROs), capture the patients' illness experience in a structured format and may help bridge the gap between patients and providers. PROs measure any aspect of patient-reported health (e.g., physical, emotional or social symptoms) and can help to direct care and improve clinical outcomes. When clinicians systematically collect patient-reported data in the right place at the right time, PRO measurement can effectively aid in detection and management of conditions, improve satisfaction with care and enhance the patient-provider relationship. This review article summarizes the latest approaches to PRO measuring for clinical trials and clinical practice, with a focus on use of PROs in gastroenterology.
\end{abstract}

(J Neurogastroenterol Motil 2013;19:137-148)

Key Words

Gastroenterology; Patient-reported outcomes; Quality of life

\section{Introduction}

Patients typically seek health care because they experience symptoms. Health care providers must elicit, measure and interpret patient symptoms as part of the clinical evaluation. Patientgenerated reports, also known as Patient-Reported Outcomes (PROs), capture the patients' illness experience in a structured format and may help bridge the gap between patients and providers. The United States Food and Drug Administration (FDA) defines a PRO as "any report of the status of a patient's health condition that comes directly from the patient, without in- terpretation of the patient's response by a clinician or anyone else." 1

PROs measure any aspect of patient-reported health (e.g., physical, emotional or social symptoms) and can help to direct care and improve clinical outcomes. When clinicians systematically collect patient-reported data in the right place at the right time, PRO measurement can effectively aid in detection and management of conditions, ${ }^{2,3}$ improve satisfaction with care ${ }^{4}$ and enhance the patient-provider relationship. ${ }^{4-8}$

In addition to their use in clinical practice, PROs also play an important role in clinical trials and other research endeavors. For example, health-related quality of life (HRQOL), a sub-type of

Received: January 4, 2013 Revised: February 25, 2013 Accepted: February 26, 2013

(c) This is an Open Access article distributed under the terms of the Creative Commons Attribution Non-Commercial License (http://creativecommons. org/licenses/by-nc/3.0) which permits unrestricted non-commercial use, distribution, and reproduction in any medium, provided the original work is properly cited.

*Correspondence: Brennan M R Spiegel, MD, MSHS

Associate Professor of Medicine, 11301 Wilshire Blvd, Bldg 115, Room 215, Los Angeles, California 90073, USA

Tel: +1-310-268-3256, Fax: +1-310-268-4510, E-mail: bspiegel@mednet.ucla.edu

Financial support: None.

Conflicts of interest: The opinions and assertions contained herein are the sole views of the authors and are not to be construed as official or as reflecting the views of the Department of Veteran Affairs. 
PRO that measures biopsychosocial health, has gained traction as an outcome in clinical research, including clinical trials. HRQOL measures can document patient improvement or decrement over time, and help to estimate the benefits of clinical interventions. In addition, the FDA now considers the patient report in drug approval, and has developed guidance for use of PROs in clinical trials. ${ }^{1}$ The National Institute of Health (NIH) has also supported a major PRO initiative, called the Patient Reported Outcome Measurement Information System (PROMIS ${ }^{\circledR}$; www. nihpromis.org), designed to develop and evaluate several HRQOL domains. ${ }^{9,10}$ I will discuss PROMIS in detail later in this article because it is now becoming the new gold standard of PRO measurement. Finally, the rising prominence of the Chronic Care Model, which emphasizes the centrality of the provider-patient relationship in clinical decision making, ${ }^{2,3}$ places the patient report front-and-center. In short, there is a confluence of scientific, regulatory and political factors that amplify the importance of PRO research.

Gastrointestinal (GI) illnesses can lead to physical, mental and social distress. ${ }^{11}$ For this reason, patients, providers, investigators and regulators are interested in using PROs to guide clinical decision-making, conduct clinical research and achieve drug approval in GI disorders. Over the last 2 decades, investigators have developed PROs that measure a range of GI symptoms, including physical, emotional and social features of digestive disorders. It is important for GI providers and researchers to be aware of existing PROs, their limitations and how they can be used.

The purpose of this article is to help guide clinicians and investigators by reviewing PRO measurement in gastroenterology. Because much of the work in PROs focuses on functional gastrointestinal disorders (FGIDs), like irritable bowel syndrome (IBS), I will intermittently focus on FGIDs as a model for how to measure and employ PROs for clinical and research purposes.

\section{Importance of Patient-Reported Outcomes in Clinical Practice}

There are at least four reasons why measuring PROs is relevant in clinical practice. First, any experienced provider knows that traditionally measured biomarkers often fail to correspond with how a patient is actually feeling. For example, in diabetes, clinicians usually measure the hemoglobin A $1 \mathrm{C}$ level. This value is often used to make treatment decisions, like how aggressively to treat the diabetes, or whether to change to a new medication.
But the problem is that some patients may have a low hemoglobin A1C but still feel listless or depressed despite their favorable laboratory values. In contrast, others with unfavorable levels may nonetheless feel upbeat and vigorous. Similarly, an IBS patient with 6 daily bowel movements may share the same problems at work (like difficulty getting the job done because of the constant bother of symptoms) as another IBS patient with 3 daily bowel movements. In both examples the traditional outcome measured by healthcare providers (e.g., hemoglobin A1C levels, bowel movement frequency) fails to capture other aspects of health. In other words, just asking about bowel movement frequency in IBS (for example) is not enough to fully understand how the disease is affecting a patient; it is only part of the picture.

A second reason to measure PROs is that patients rarely value traditional biomarkers in the same manner as providers. For example, patients with hypertension often fail to share the same enthusiasm as their providers in achieving specific blood pressure goals, but are quick to comply with therapy when their hypertension leads to headaches or dizziness. Similarly, some patients with chronic constipation could care less if their therapy allows them to achieve an increase of 1 or 2 more bowel movements per week, but care greatly if the improvement also allows them to eat dinner without worrying about the consequences of their food selection. Measuring HRQOL, in particular, directly acknowledges that patients often value different outcomes than their providers.

Third, PROs provide a key component to understanding the true burden of any disease. Traditional measures of disease burden include the prevalence of a disease, direct and indirect expenditures of a disease, and the worker productivity decrements related to a disease. However, in order to fully appreciate the true burden of a disease, it is also important to appreciate the HRQOL decrement engendered by the disease. The notion of "weighting" diseases not only by their cost and prevalence but also by their HRQOL decrement has an innate sense of fairness and is a fundamental principle of health economics. ${ }^{12}$ This is important, because it suggests that society and health providers are willing to spend more money to cure diseases that severely impact HRQOL than diseases that only moderately impact HRQOL. For this reason alone it is critical to carefully understand the HRQOL decrement of various diseases, because that information may have policy implication when it comes to developing a healthcare budget.

Fourth, PROs are especially important in diseases that are marked by morbidity, but not mortality. If we only emphasized 
the care of diseases that are mortal, then most of the world would be without treatment, since, thankfully, many diseases do not cause death. Fortunately, the FGIDs, like IBS, are not mortal diseases. But that does not mean that they are not important, or that they are just a "nuisance" that should be disregarded. To the contrary, FGIDs can severely affect HRQOL. Without measuring PROs like HRQOL, it would be unfair to conclude that FGIDs are simply a "nuisance" because they are not mortal diseases like cancer. This is distinguished from diseases where HRQOL really has no important role, such as in patients with an acute gallstone, or patients with an exsanguinating peptic ulcer. These are conditions where acute treatment must be rendered, regardless of how the HRQOL is affected at the moment of illness. We do not administer "feeling thermometers" or HRQOL questionnaires in patients with an active ulcer bleed or a gallstone obstruction - we manage the disease immediately regardless of precise PRO data. In contrast, PROs have large clinical relevance in patients with disorders like chronic migraine headache, fibromyalgia or depression. The FGIDs share characteristics with these latter conditions, since they uniformly affect quality but not quantity of life. Thus, failing to acknowledge PROs in chronic conditions like the FGIDs is a dangerous approach, because it tends to minimize the importance of these conditions.

\section{Measuring Patient-Reported Outcomes -}

PROs are usually measured with patient questionnaires, or so-called "instruments." PRO instruments may collect data across several areas of health, including physical, psychological and social functioning. PRO instruments are generally classified as either "generic" or "disease-targeted." ${ }^{12}$ Generic instruments are questionnaires that were developed to measure PROs across many different conditions. In contrast, disease-targeted instruments are designed to target one or more specific conditions. Examples of the former include the short form-36 health survey $(\mathrm{SF}-36)^{13}$ and the sickness impact profile. ${ }^{14}$ As generic instruments, the SF-36 and sickness impact profile were designed to measure health across a range of conditions rather than specific individual conditions. For example, the SF-36 has been used to measure health in over 100 conditions ranging from hepatitis $\mathrm{C}$ to colon cancer to IBS. As with other balanced HRQOL instruments, the SF-36 measures health across several areas, including mental, physical and social health. The instrument includes 36 items (thus the " 36 " of "SF-36") that are organized into 8 discrete scales, such as "physical functioning," "vitality," or "bodily pain." Each scale can be scored from 0 to 100, with higher scores indicating a better HRQOL. In this manner, any patient can be assigned a set of values to measure their HRQOL, much like a vital sign. The SF-36 is particularly useful in FGIDs because it captures areas that are deemed important by patients with FGIDs, including bodily pain, energy/fatigue and social functioning. In particular, the SF-36 contains several items pertaining to "vital exhaustion," including the degree of feeling "full of life," feeling "worn out" and feeling "tired." Because vital exhaustion is thought to be a critical component of the biology of FGIDs like IBS, ${ }^{15}$ the SF-36 is an example of an appropriate generic instrument to use in measuring PROs in FGIDs.

Beyond generic PRO instruments, there have been over 110 disease-targeted PROs developed in gastroenterology. The PROs cover a range of conditions, including achalasia, ${ }^{16}$ celiac sprue, ${ }^{17,18}$ dyspepsia, ${ }^{19-36}$ eosinophilic esophagitis, ${ }^{37}$ fecal incontinence, ${ }^{38-53}$ functional GI disorders, ${ }^{18,34,42,46,53-79}$ GERD, ${ }^{23,31-33,36,80-102}$ GI malignancies, ${ }^{41,70,103-107}$ post gastrectomy, ${ }^{105,108}$ ileal conduit diversion, ${ }^{109}$ ileostomy, ${ }^{110}$ inflammatory bowel disease, ${ }^{111-119}$ pregnancy-related GI symptoms, ${ }^{120-122}$ systemic sclerosis ${ }^{123}$ and radiation enteritis, ${ }^{50}$ among others. Thirteen of the PROs apply to the pediatric population, $37,38,53,70,73,90,93,95,107,115,116,124,125$ and 6 apply specifically to women. ${ }^{49,120-122,126,127}$

There have been several PROs designed for the FGIDs. ${ }^{128}$ These instruments vary in content, length and degree of data supporting their validity for use in clinical practice. Of the multiple disease-targeted instruments in FGIDs, the IBS quality of life (IBS-QOL) questionnaire, ${ }^{66}$ originally developed by Patrick and Drossman, has the most extensive data supporting its validity. In particular, the IBS-QOL can be used to measure patient HRQOL over time, and the change in IBS-QOL scores often correlate with other important features of health. In this manner, providers could use the IBS-QOL to follow their patient longitudinally to complement traditionally measured parameters. In addition, the IBS-QOL has been used in clinical treatment trials to help determine whether specific therapies improve HRQOL. This type of information is critical, because treatments that improve only 1 or 2 symptoms might not be useful if they cannot simultaneously improve HRQOL.

\section{Estimating Health-related Quality of Life in Clinical Practice}

Despite all the academic and practical reasons to measure PROs in clinical practice, most providers do not routinely admin- 
ister PRO instrument. There are several reasons why. First, many providers find it burdensome. In order to accurately measure PROs, providers must perform a thorough evaluation of multiple physical, psychological and social areas of health.Validated instruments like the SF-36 or IBS-QOL are designed to capture information from each of these areas of health in order to establish a broad and balanced portrait of a patient's unique health status. However, these measures are primarily designed for research purposes, and clinicians rarely have the time or inclination to assess PROs with this degree of detail. Second, most healthcare providers, including gastroenterologists, have not received training in how to perform a complete "biopsychosocial" evaluation, ${ }^{129}$ in which they take the time not only to ask about individual physical symptoms, but also to determine whether and how the disease causes emotional or social distress. ${ }^{11}$ Indeed, studies indicate that this type of history taking is often not performed. Third, many providers question whether PRO data are clinically "actionable." Without knowing how to employ PRO data, some clinicians question the value of routinely collecting PRO information as part of everyday care.

In light of this reality, it is important to arm providers with a concise list of questions that can help them rapidly understand their patients PRO status. Moreover, it is important to show how knowing this information can help drive treatment decisions by allowing providers to gain better insight into their patients' overall health. This leads to a discussion of the NIH PROMIS system - a novel approach to measuring PROs for research and clinical practice.

\section{Overview of NIH PROMIS}

In 2002, the NIH made a renewed commitment to chart a "roadmap" for medical research into the 21 st century. Through a series of planning meetings with multiple stakeholders, the NIH identified gaps in biomedical science and research, and prioritized major areas of inquiry that cut across all of human health. The idea was to develop a mechanism to support research that no single NIH institute could handle on its own. The ultimate goal of the roadmap initiative was to jump-start the biomedical research enterprise in the U.S., re-engineer it to help meet the modern realities of healthcare, and ultimately deliver a set of tools that can improve individual and public health in tangible and measurable ways.

PROMIS was a major program that emerged from the roadmap initiative. ${ }^{10}$ Sponsored in 2004, PROMIS was launched with the goal of building, validating and disseminating a toolbox of publically available item banks capable of measuring PROs across the breadth and depth of the human illness experience. To accomplish this, the NIH sponsored a consortium of centers to work collaboratively to develop PROs for public use. To ensure harmonization of efforts, all the PROMIS sites were mandated to employ the same package of rigorous methodologies while building their PRO item banks. Moreover, the resulting PROs would be different from traditional paper-and-pencil questionnaires. Instead, the PROMIS item banks were intended from the start to be administered electronically, and to employ item response theory (IRT) with computerized adaptive testing (CAT). ${ }^{130,131}$ The PROMIS vision was to use these modern techniques to create highly efficient and very short questionnaires that could be easily implemented in busy clinical systems while preserving reliability and validity (more on IRT and CAT, below).

There are currently over 10 primary research centers that comprise the PROMIS network. Our unit at the University of California, Los Angeles, is the PROMIS site focused on measuring GI-related symptoms. Each PROMIS site is unified by the same "PROMIS standards" of methodology. A statistical coordinating center, based at Northwestern University in Chicago, supports and administers the online "Assessment Center" program that holds the PROMIS item banks. Through Assessment Center, PROMIS investigators, other researchers, industry and clinical sites can use the existing PROMIS item banks for their clinical and research purposes. Refer to the PROMIS website at www.nihpromis.gov for more information on the full set of freely-available item banks, the conceptual framework of all PROMIS domains (including completed domains and those under construction) and for more information on Assessment Center and its functions.

\section{The Promise of PROMIS}

The PROMIS effort was borne from the realization that patients are the ultimate consumer of healthcare, and are the final judge of whether our healthcare is working. Moreover, patients seek healthcare because of symptoms, as noted in earlier in this article. Healthcare providers, in turn, are charged with eliciting, measuring, and interpreting these symptoms to direct clinical decision-making. But this is easier said than done. ${ }^{132}$ Although understanding the patient report serves a vital role in directing care, most providers have opted for ad hoc and informal measurement 
of symptoms and function. Yet there have been extensive efforts to develop and apply reliable and valid PRO measures across diseases, with a special focus on chronic illnesses. ${ }^{4,9,133}$

Although there have been many efforts to bring PRO data to the clinical setting, as reviewed extensively elsewhere, ${ }^{4,132-136}$ a confluence of events, coupled with advancements in PRO measurement techniques, justifies re-evaluating the role of PROs in clinical practice. In particular, advances in computing and information technology permit inexpensive and seamless data collection and processing, facilitating both previously unimaginable individualization and efficient data delivery to healthcare providers. Systematic collection of patient reported data promises to inform other aspects of the evolving Chronic Care Model, such as routine database driven practice audits. With increasing development and dissemination of electronic medical record systems, there are more opportunities than ever to integrate PRO data into everyday clinical practice.

In this context, the NIH launched PROMIS to develop and validate a toolbox of PROs spanning most illness domains, as noted above., ${ }^{9,10}$ Using modern psychometric techniques, such as IRT and CAT, ${ }^{130,131}$ PROMIS is an example system that offers the potential for addressing modern PRO measurement needs, establishing common-language benchmarks for symptoms across conditions, and identifying clinical thresholds for action and meaningful improvement or decline. The FDA and NIH are currently in discussions to evaluate whether and how PROMIS item banks can help fit regulatory objectives in drug approval. In short, there is now a confluence of scientific, regulatory, and political factors that amplify the importance of PRO research, and PROMIS finds itself in the midst of this confluence with rigorously developed PROs to assist end-users (most importantly and patients themselves).

Despite the unprecedented opportunities for realizing the vision of collecting PRO data in routine clinical care, we must again recognize the practical challenges to this vision; Table lists several of these well-acknowledged challenges, described in previous reviews. ${ }^{132,134,135}$ However, NIH PROMIS investigators believe these challenges can now be adequately met, and that the time has come to parlay modern advancements in PRO science to overcome these obstacles. I have coupled each challenge in Table with possible solutions, along with providing examples of how the challenges are being overcome.

Table. Traditional Challenges to Using Patient-Reported Outcome Data in Clinical Practice (Each Challenge Is Coupled With Potential Solutions, Along With an Example of How the Challenge Is Being Addressed)

Traditional challenge to using PRO data in clinical practice

It is time consuming for both providers and patients to collect PRO data, Use IRT to develop very short and efficient questionnaires; allow patients making it untenable for use in everyday clinical practice.

There are too many PROs to choose from, and lack of a measurement standards across PROs.

It is time consuming and difficult to score PRO data and place the information in the chart.

PRO scores can be hard for clinicians to efficiently understand.

Clinicians may not understand how to act upon PRO scores. to complete these short questionnaires with a personal computer, touch pad, tablet or other modern electronic device. PROMIS offers IRT-based questionnaires across a range of major health domains (www.nihpromis.org).

Develop common metrics for classifying and comparing patients to one another across diseases; ensure these metrics are developed with the same rigorous standards. PROMIS offers potential to select from a toolbox of PROs that apply across conditions, and that have been rigorously developed with a consistent set of methods across instruments.

Develop automated systems for scoring electronically inputted patient data; design methods for seamlessly transmitting scores into electronic health records, where available. PROMIS investigators are working on techniques to carryout these complex functions.

Partner with end-users to develop score reports that are acceptable and easily interpretable by health care providers.

Ensure PRO data are clinically applicable to individual patients (i.e., provide PRO data that is useful, and nothing else); ensure PRO data are tied to a clinical action plan; establish clinical thresholds for action and meaningful improvement or decline. PROMIS includes a clinical practice working group charged with the mission of creating deliverables that are of use to clinical end-users.

PRO, Patient-Reported Outcome; PROMIS, Patient Reported Outcome Measurement Information System; IRT, item response theory. 


\section{Brief Overview of Employ Item Response Theory and Computerized Adaptive Testing Methodology}

The success of PROMIS is firmly rooted in its use of IRT and CAT. A full review of these techniques is well beyond the scope of this brief overview - for a detailed discussion, refer to these citations. ${ }^{130,131}$ In short, IRT is often referred to as "modern psychometric theory," in contrast to "classic test theory," or CTT. The basic idea behind both IRT and CTT is that there is some latent construct, or "trait," underlying an illness experience. This construct cannot be directly measured, but can be indirectly measured by creating items that are scaled and scored. For example, "fatigue," "pain," "GI distress" or even "happiness" are latent constructs - we cannot take a picture of these things, run a blood test for these things, or obtain an X-ray to view these things. But we know they exist. People can experience more or less of these constructs, which can be measured along a continuous scale. We can infer the amount of a latent construct by measuring it indirectly with individual items. These items, in turn, can be rolled into scores using a variety of algorithms.

Although both IRT and CTT assume the presence of an underlying, unobservable, latent trait, the techniques diverge when it comes to how the trait is measured. The main difference between IRT and CTT is that the former can support CAT, whereas the latter does not; this is the beauty of IRT.

In a CAT-administered item bank, patients all view the same initial item. However, depending on the respondent's answer to the first item, the computer selects a tailored second item - i.e., it adapts based on the respondent's input. This process continues, based on an underlying algorithm, until the computer is satisfied that it has a good sense of the amount of some underlying construct (e.g., fatigue). The computer is usually able to figure this out quickly, and the patient can typically answer far fewer questions than would be necessary with CTT, in which a full questionnaire is administered from start to finish, no matter what, and the score is based off the full set of items.

So how does CAT work? It can only work if there is an underlying IRT algorithm. Whereas CTT asks: “Given a person's total score on a questionnaire, what is the respondent's level on the trait being measured?", IRT asks: "Given what is known about the unique set of items viewed and individual responses to those items, what is the respondent's most likely level of the trait being measured." So, CTT deals with total scores based on all items, whereas IRT deals with individual item responses. Furthermore, IRT employs those responses to estimate a likely score without having to use all the items in the full questionnaire.

The mathematics of IRT is fairly complex, and reviewed elsewhere. ${ }^{130}$ But the basic idea is that IRT assumes there is a natural order of difficulty of items in an item bank. This is not difficulty in the usual sense, like one examination question being "harder" than another. Here, difficulty refers to the likelihood of reaching a certain level of illness severity. For example, walking 10 feet is less difficult than walking 10 miles - those have an obvious order. In GI, having reflux symptoms alone would be ordered lower than having reflux with dysphagia. And bowel urgency alone would be ordered lower than urgency with bowel incontinence. Similarly, nausea with vomiting would be ranked higher than mere "queasiness" alone, although these symptoms are arranged along a spectrum. So, the idea is that items can be rank-ordered along a continuum of difficulty, and this ordering is fundamental to IRT.

In order for IRT to work, each item is assigned a variety of parameters. One parameter, already discussed above, is the difficulty of the item. Another important concept is the item discrimination parameter. This parameter models the rate of increase in the probability of endorsing an item as the amount of underlying trait increases; it indicates the strength of association between an individual item and the overall trait being measured. Highly discriminating items can reliably identify patients with small but measurable differences in a trait along a continuum.

Using the difficulty and discrimination parameters of items in a bank, CAT can pick-and-choose items that a patient will view, and quickly hone in on a trait-level estimate. With just a few steps, the IRT algorithm can employ CAT to predict, with a high degree of accuracy, what the patient would have scored had they completed the entire questionnaire.

\section{Development of PROMIS Gastrointestinal Symptoms Item Bank}

Our group at UCLA is developing the GI Symptom item bank for PROMIS. The final product will yield a set of publically available, CAT-administered item banks capable of measuring GI symptoms across several domains (Fig. 1). We are evaluating the performance of these item banks using both cross-sectional and longitudinal cohorts; the latter is important to evaluate whether the item banks can detect meaningful change over time. We are working to capture the breadth and depth of physical 
Domain

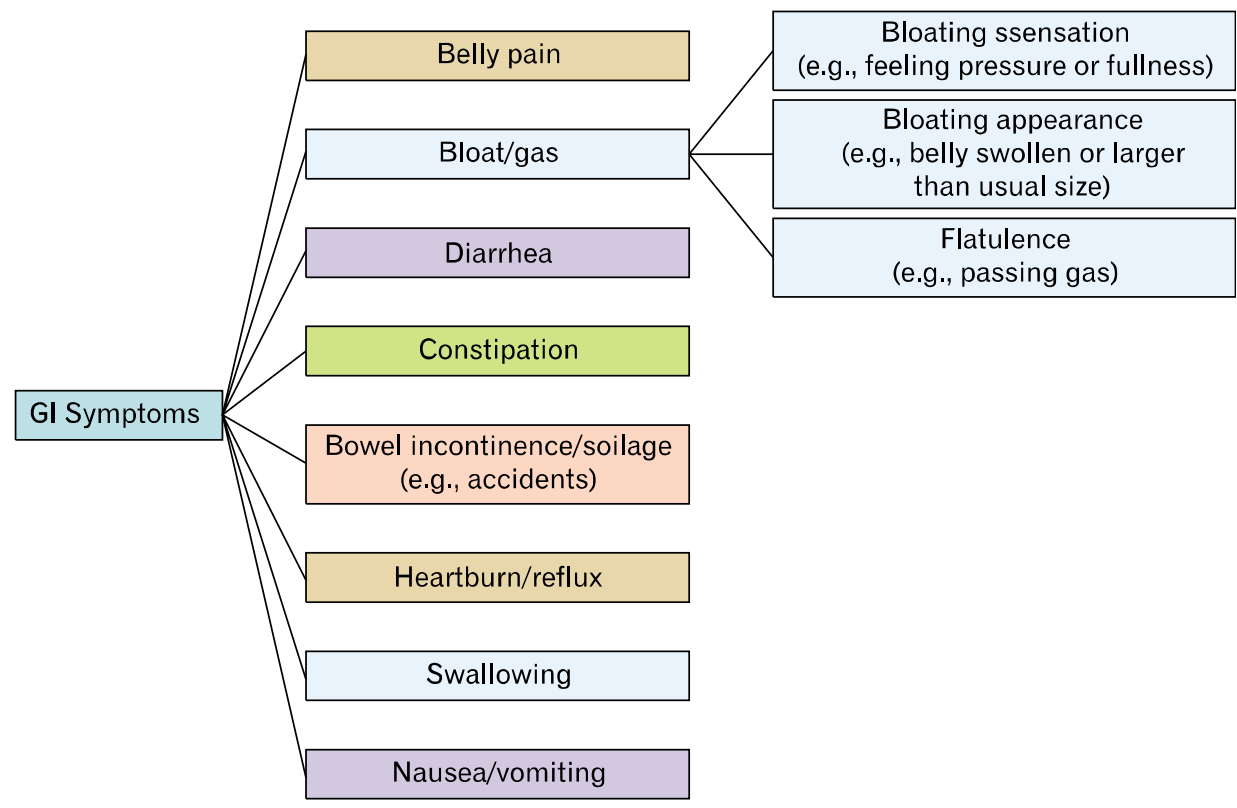

Figure 1. Conceptual model of gastrointestinal (GI) symptoms underlying GI PROMIS item bank development. PROMIS, Patient Reported Outcome Measurement Information System.

Interpretation: Your answered questions about each of $8 \mathrm{GI}$ symptoms. The answers were scored and then combined to form $8 \mathrm{GI}$ symptom scales, represented as percentile scores (ranging from 1-100) based on the U.S. general population (higher $=$ worse). This "heat map" shows your symptom scores reported within severity quartiles (red bars). The symptoms are presented from most to least severe, based on comparison with the U.S. population.

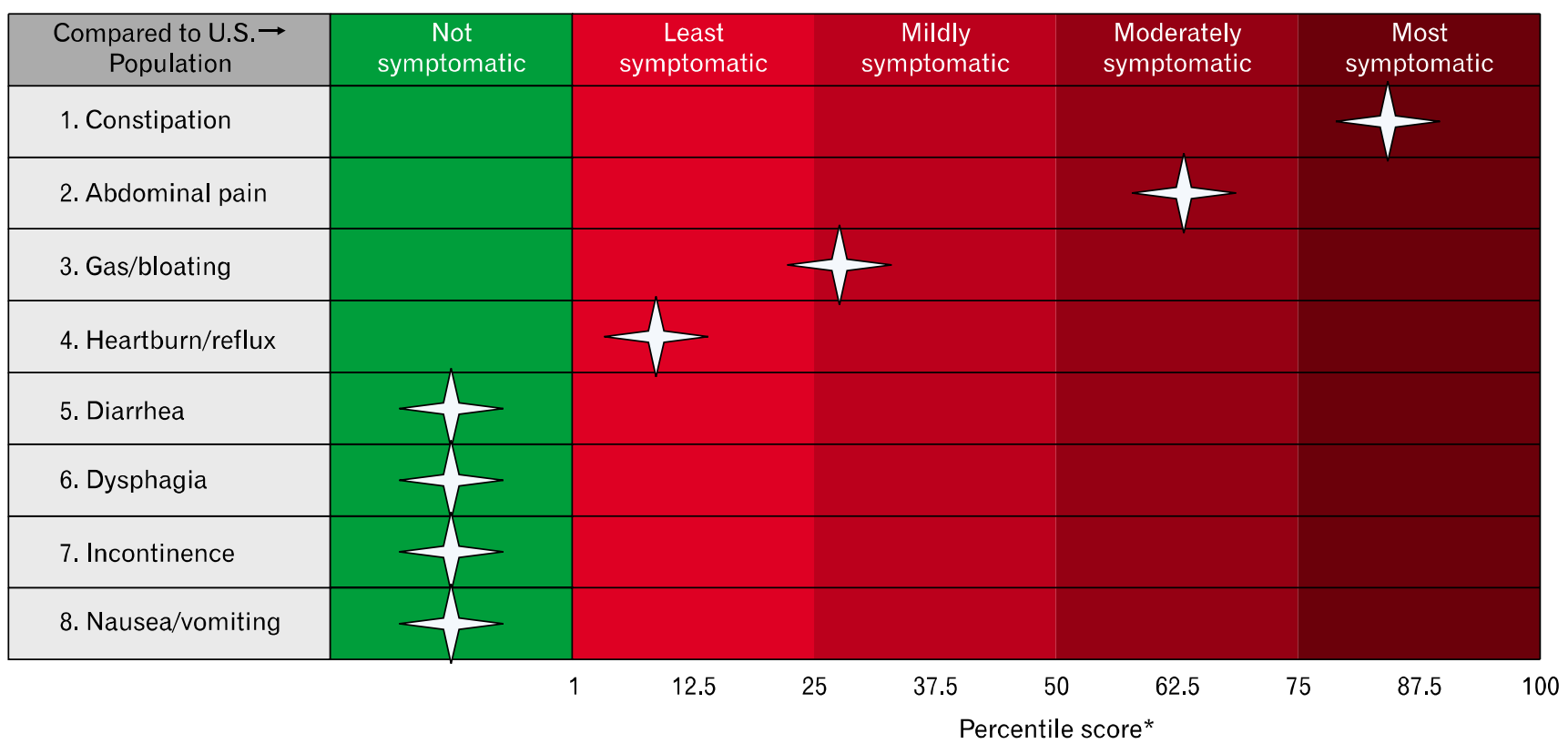

*Each composite score is expressed as a percentile rank compared to people in the U.S. population reporting the same symptom. The scores are presented within severity quartiles (red bars).

Figure 2. Sample "heat map" patient report of gastrointestinal Patient Reported Outcome Measurement Information System (GI PROMIS) scores. Patients complete PROMIS items at home or in the waiting room using a tablet device, and the results are converted into a report available in the electronic health record. In this case, patients are compared to the general U.S. population benchmarks to add interpretability to the scores, similar to a laboratory test. 
symptoms associated with GI involvement, including the multiple dimensions of those symptoms (e.g., frequency, severity, bothersomeness, predictability and duration etc.). This item bank, due for completion in mid 2013, will be applicable to both the general population, and to patients with a defined GI illness. It will be a system-targeted item bank that measures physical symptoms of the GI tract; it will not be a disease-targeted item bank. This is an important distinction of PROMIS, because disease-targeted item banks are not useful across the population as a whole. PROMIS aims to support item banks that are applicable to all comers.

The conceptual framework in Figure 1 represents our current understanding of GI symptoms. This model has been principally informed by structured cognitive interviews we conducted in over 120 patients with IBS, published elsewhere, ${ }^{137}$ coupled with systematic literature searches and expert opinion. In our PROMIS work we found that this model applies across all conditions marked by GI symptoms - not just IBS.

The current GI PROMIS framework posits that GI Symptoms are captured by 8 domains: (1) Belly pain, (2) Bloat/gas, (3) Diarrhea, (4) Constipation, (5) Bowel incontinence/soilage, (6) Heartburn/reflux, (7) Swallowing and (8) Nausea/vomiting.

\section{Future Vision of Gastrointestinal PROMIS -}

These PROMIS item banks may ultimately be employed in several settings, including clinical practice, research and clinical trials. The item banks will be especially useful in clinical practice given their highly efficient nature, and the ability to place the CAT-administered questionnaires on web-based electronic media, such as laptops, smart phones or tablets.

These electronic patient-provider portals $\left(\mathrm{P}^{3} \mathrm{~s}\right)$ are changing how we deliver healthcare. ${ }^{138}$ Using $\mathrm{P}^{3}$ s, patients interact with their providers within the comfort of their own home; this expands the care model beyond face-to-face visits, and allows patients to self-report symptoms and other illness experiences (e.g., "psychomarkers") to complement traditional biomarkers. Providers review the reports through an electronic health record, and then collaborate with patients to make shared health decisions. $\mathrm{P}^{3}$ s can also use algorithms to prepare tailored "educational prescriptions" by drawing from a library of online resources. This process can be user-friendly, empowering to patients and ultimately improve patient-provider communication.

Figure 2 shows a sample report developed with input from GI physicians. Patients will complete the PROMIS GI item banks using a $\mathrm{P}^{3}$ system, and then the data will be converted to a report for providers to review directly from the electronic health record. This type of interface can change how we monitor patients in the context of everyday clinical practice, and translate academic theory into tools we can employ to improve patient outcomes.

\section{References}

1. Burke LB, Kennedy DL, Miskala PH, Papadopoulos EJ, Trentacosti AM. The use of patient-reported outcome measures in the evaluation of medical products for regulatory approval. Clin Pharmacol Ther 2008;84:281-283.

2. Wagner EH, Austin BT, Von Korff M. Organizing care for patients with chronic illness. Milbank Q 1996;74:511-544.

3. Wagner EH, Austin BT, Davis C, Hindmarsh M, Schaefer J, Bonomi A. Improving chronic illness care: translating evidence into action. Health Aff (Millwood) 2001;20:64-78.

4. Marshall S, Haywood K, Fitzpatrick R. Impact of patient-reported outcome measures on routine practice: a structured review. J Eval Clin Pract 2006;12:559-568.

5. Dobscha SK, Gerrity MS, Ward MF. Effectiveness of an intervention to improve primary care provider recognition of depression. Eff Clin Pract 2001;4:163-171.

6. Taenzer P, Bultz BD, Carlson LE, et al. Impact of computerized quality of life screening on physician behaviour and patient satisfaction in lung cancer outpatients. Psychooncology 2000;9:203213.

7. Velikova G, Booth L, Smith AB, et al. Measuring quality of life in routine oncology practice improves communication and patient well-being: a randomized controlled trial. J Clin Oncol 2004;22: 714-724.

8. Detmar SB, Muller MJ, Schornagel JH, Wever LD, Aaronson NK. Health-related quality-of-life assessments and patient-physician communication: a randomized controlled trial. JAMA 2002; 288:3027-3034.

9. Reeve BB, Hays RD, Bjorner JB, et al. Psychometric evaluation and calibration of health-related quality of life item banks: plans for the Patient-Reported Outcomes Measurement Information System (PROMIS). Med Care 2007;45(5 suppl 1):S22-S31.

10. Cella D, Yount S, Rothrock N, et al. The Patient-Reported Outcomes Measurement Information System (PROMIS): progress of an NIH Roadmap cooperative group during its first two years. Med Care 2007;45(5 suppl 1):S3-S11.

11. Spiegel BM, Khanna D, Bolus R, Agarwal N, Khanna P, Chang L. Understanding gastrointestinal distress: a framework for clinical practice. Am J Gastroenterol 2011;106:380-385.

12. Guyatt GH, Feeny DH, Patrick DL. Measuring health-related quality of life. Ann Intern Med 1993;118:622-629.

13. Ware JE Jr, Sherbourne CD. The MOS 36-item short-form health survey (SF-36). I. Conceptual framework and item selection. Med Care 1992;30:473-483.

14. Bergner M, Bobbitt RA, Carter WB, Gilson BS. The Sickness Impact Profile: development and final revision of a health status 
measure. Med Care 1981;19:787-805.

15. Mayer EA. The neurobiology of stress and gastrointestinal disease. Gut 2000;47:861-869.

16. Urbach DR, Tomlinson GA, Harnish JL, Martino R, Diamant NE. A measure of disease-specific health-related quality of life for achalasia. Am J Gastroenterol 2005;100:1668-1676.

17. Cranney A, Zarkadas M, Graham ID, Switzer C. The Canadian celiac health survey - the Ottawa chapter pilot. BMC Gastroenterol 2003;3:8.

18. Hauser W, Gold J, Stein J, Caspary WF, Stallmach A. Health-related quality of life in adult coeliac disease in Germany: results of a national survey. Eur J Gastroenterol Hepatol 2006;18:747-754.

19. De Luca L, Zagari RM, Pozzato P, et al. Measuring dyspepsia: a new severity index validated in Bologna. Dig Liver Dis 2004;36: 806-810.

20. Leidy NK, Farup C, Rentz AM, Ganoczy D, Koch KL. Patient-based assessment in dyspepsia: development and validation of Dyspepsia Symptom Severity Index (DSSI). Dig Dis Sci 2000; 45:1172-1179.

21. Madsen LG, Hansen JM, Grønvold M, Bytzer P. The validity of a symptom diary in ratings of dyspepsia measured against a detailed interview: do patients and clinicians agree in their assessment of symptoms? Aliment Pharmacol Ther 2007;26:905-912.

22. Mujakovic S, de Wit NJ, van Marrewijk CJ, et al. Psychopathology is associated with dyspeptic symptom severity in primary care patients with a new episode of dyspepsia. Aliment Pharmacol Ther 2009;29:580-588.

23. Rothman M, Farup C, Stewart W, Helbers L, Zeldis J. Symptoms associated with gastroesophageal reflux disease: development of a questionnaire for use in clinical trials. Dig Dis Sci 2001;46:15401549.

24. Kulich KR, Malfertheiner P, Madisch A, et al. Psychometric validation of the German translation of the Gastrointestinal Symptom Rating Scale (GSRS) and Quality of Life in Reflux and Dyspepsia (QOLRAD) questionnaire in patients with reflux disease. Health Qual Life Outcomes 2003;1:62.

25. Adam B, Liebregts T, Saadat-Gilani K, Vinson B, Holtmann G. Validation of the gastrointestinal symptom score for the assessment of symptoms in patients with functional dyspepsia. Aliment Pharmacol Ther 2005;22:357-363.

26. Revicki DA, Rentz AM, Dubois D, et al. Gastroparesis Cardinal Symptom Index (GCSI): development and validation of a patient reported assessment of severity of gastroparesis symptoms. Qual Life Res 2004;13:833-844.

27. Hu WH, Lam KF, Wong YH, et al. The Hong Kong index of dyspepsia: a validated symptom severity questionnaire for patients with dyspepsia. J Gastroenterol Hepatol 2002;17:545-551.

28. Talley NJ, Haque M, Wyeth JW, et al. Development of a new dyspepsia impact scale: the Nepean Dyspepsia Index. Aliment Pharmacol Ther 1999;13:225-235.

29. Sander GB, Mazzoleni LE, Francesconi CF, et al. Development and validation of a cross-cultural questionnaire to evaluate nonulcer dyspepsia: the Porto Alegre Dyspeptic Symptoms Questionnaire (PADYQ). Dig Dis Sci 2004;49:1822-1829.

30. de la Loge C, Trudeau E, Marquis P, et al. Cross-cultural development and validation of a patient self-administered questionnaire to assess quality of life in upper gastrointestinal disorders: the PAGIQOL. Qual Life Res 2004;13:1751-1762.

31. Revicki DA, Rentz AM, Tack J, et al. Responsiveness and interpretation of a symptom severity index specific to upper gastrointestinal disorders. Clin Gastroenterol Hepatol 2004;2:769-777.

32. Armstrong D, Veldhuyzen SJ, Chung SA, et al. Validation of a short questionnaire in English and French for use in patients with persistent upper gastrointestinal symptoms despite proton pump inhibitor therapy: the PASS (Proton pump inhibitor Acid Suppression Symptom) test. Can J Gastroenterol 2005;19:350-358.

33. Wiklund IK, Junghard O, Grace E, et al. Quality of Life in Reflux and Dyspepsia patients. Psychometric documentation of a new disease-specific questionnaire (QOLRAD). Eur J Surg 1998;583(suppl):41-49.

34. Mouzas IA, Fragkiadakis N, Moschandreas J, et al. Validation and results of a questionnaire for functional bowel disease in outpatients. BMC Public Health 2002;2:8.

35. Arslan G, Lind R, Olafsson S, Florvaag E, Berstad A. Quality of life in patients with subjective food hypersensitivity: applicability of the 10-item short form of the Nepean Dyspepsia Index. Dig Dis Sci 2004;49:680-687.

36. Fraser A, Delaney BC, Ford AC, Qume M, Moayyedi P. The Short-Form Leeds Dyspepsia Questionnaire validation study. Aliment Pharmacol Ther 2007;25:477-486.

37. Flood EM, Beusterien KM, Amonkar MM, et al. Patient and caregiver perspective on pediatric eosinophilic esophagitis and newly developed symptom questionnaires*. Curr Med Res Opin 2008; 24:3369-3381.

38. Brandt ML, Daigneau C, Graviss EA, Naik-Mathuria B, Fitch ME, Washburn KK. Validation of the Baylor Continence Scale in children with anorectal malformations. J Pediatr Surg 2007;42: 1015-1021; discussion 1021.

39. de Cássia Domansky R, de Gouveia Santos VL. Cross-cultural adaptation and validation of the Portuguese version of the Bowel Function in the Community instrument. J Wound Ostomy Continence Nurs 2007;34:671-677.

40. Krysa J, Lyons M, Williams AB. A simple quality of life questionnaire for patients with faecal incontinence. Int J Colorectal Dis 2009;24:1213-1217.

41. Temple LK, Bacik J, Savatta SG, et al. The development of a validated instrument to evaluate bowel function after sphincter-preserving surgery for rectal cancer. Dis Colon Rectum 2005;48:13531365.

42. Bakx R, Sprangers MA, Oort FJ, et al. Development and validation of a colorectal functional outcome questionnaire. Int $\mathrm{J}$ Colorectal Dis 2005;20:126-136.

43. Macmillan AK, Merrie AE, Marshall RJ, Parry BR. Design and validation of a comprehensive fecal incontinence questionnaire. Dis Colon Rectum 2008;51:1502-1522.

44. Due U, Ottesen M. The Danish anal sphincter rupture questionnaire: validity and reliability. Acta Obstet Gynecol Scand 2009; 88:36-42.

45. Lukacz ES, Lawrence JM, Buckwalter JG, Burchette RJ, Nager $\mathrm{CW}$, Luber KM. Epidemiology of prolapse and incontinence questionnaire: validation of a new epidemiologic survey. Int Urogynecol J Pelvic Floor Dysfunct 2005;16:272-284.

46. Bharucha AE, Locke GR 3rd, Seide BM, Zinsmeister AR. A new 
questionnaire for constipation and faecal incontinence. Aliment Pharmacol Ther 2004;20:355-364.

47. Reilly WT, Talley NJ, Pemberton JH, Zinsmeister AR. Validation of a questionnaire to assess fecal incontinence and associated risk factors: fecal Incontinence Questionnaire. Dis Colon Rectum 2000; 43:146-153; discussion 153-154.

48. Rockwood TH, Church JM, Fleshman JW, et al. Fecal Incontinence Quality of Life Scale: quality of life instrument for patients with fecal incontinence. Dis Colon Rectum 2000;43:9-16; discussion 16-17.

49. Bug GJ, Kiff ES, Hosker G. A new condition-specific health-related quality of life questionnaire for the assessment of women with anal incontinence. BJOG 2001;108:1057-1067.

50. Abayomi J, Kirwan J, Hackett A. The prevalence of chronic radiation enteritis following radiotherapy for cervical or endometrial cancer and its impact on quality of life. Eur J Oncol Nurs 2009;13: 262-267.

51. Khanna D, Hays RD, Maranian P, et al. Reliability and validity of the University of California, Los Angeles Scleroderma Clinical Trial Consortium Gastrointestinal Tract Instrument. Arthritis Rheum 2009;61:1257-1263.

52. Bols EM, Hendriks EJ, Deutekom M, Berghmans BC, Baeten $\mathrm{CG}$, de Bie RA. Inconclusive psychometric properties of the Vaizey score in fecally incontinent patients: a prospective cohort study. Neurourol Urodyn 2010;29:370-377.

53. Nanigian DK, Nguyen T, Tanaka ST, Cambio A, DiGrande A, Kurzrock EA. Development and validation of the fecal incontinence and constipation quality of life measure in children with spina bifida. J Urol 2008;180(4 suppl):1770-1773; discussion 1773.

54. Roalfe AK, Roberts LM, Wilson S. Evaluation of the Birmingham IBS symptom questionnaire. BMC Gastroenterol 2008;8:30.

55. Wiklund IK, Fullerton S, Hawkey CJ, et al. An irritable bowel syndrome-specific symptom questionnaire: development and validation. Scand J Gastroenterol 2003;38:947-954.

56. van der Veek PP, Van Rood YR, Masclee AA. Symptom severity but not psychopathology predicts visceral hypersensitivity in irritable bowel syndrome. Clin Gastroenterol Hepatol 2008;6:321-328.

57. Schmulson M, Ortiz O, Mejia-Arangure JM, et al. Further validation of the IBS-QOL: female Mexican IBS patients have poorer quality of life than females from North Carolina. Dig Dis Sci 2007; 52:2950-2955.

58. Jones MP, Keefer L, Bratten J, et al. Development and initial validation of a measure of perceived stigma in irritable bowel syndrome. Psychol Health Med 2009;14:367-374.

59. Bengtsson M, Ohlsson B, Ulander K. Development and psychometric testing of the Visual Analogue Scale for Irritable Bowel Syndrome (VAS-IBS). BMC Gastroenterol 2007;7:16.

60. Labus JS, Bolus R, Chang L, et al. The Visceral Sensitivity Index: development and validation of a gastrointestinal symptom-specific anxiety scale. Aliment Pharmacol Ther 2004;20:89-97.

61. Reilly MC, Bracco A, Ricci JF, Santoro J, Stevens T. The validity and accuracy of the Work Productivity and Activity Impairment questionnaire - irritable bowel syndrome version (WPAI:IBS). Aliment Pharmacol Ther 2004;20:459-467.

62. Luther SL, Nelson AL, Harrow JJ, Chen F, Goetz LL. A comparison of patient outcomes and quality of life in persons with neuro- genic bowel: standard bowel care program vs colostomy. J Spinal Cord Med 2005;28:387-393.

63. Svedlund J, Sjodin I, Dotevall G. GSRS - a clinical rating scale for gastrointestinal symptoms in patients with irritable bowel syndrome and peptic ulcer disease. Dig Dis Sci 1988;33:129-134.

64. Wong E, Guyatt GH, Cook DJ, Griffith LE, Irvine EJ. Development of a questionnaire to measure quality of life in patients with irritable bowel syndrome. Eur J Surg 1998;583(suppl):50-56.

65. Groll D, Vanner SJ, Depew WT, et al. The IBS-36: a new quality of life measure for irritable bowel syndrome. Am J Gastroenterol 2002;97:962-971.

66. Patrick DL, Drossman DA, Frederick IO, DiCesare J, Puder KL. Quality of life in persons with irritable bowel syndrome: development and validation of a new measure. Dig Dis Sci 1998;43:400411.

67. Hahn BA, Kirchdoerfer LJ, Fullerton S, Mayer E. Evaluation of a new quality of life questionnaire for patients with irritable bowel syndrome. Aliment Pharmacol Ther 1997;11:547-552.

68. Gordon S, Ameen V, Bagby B, Shahan B, Jhingran P, Carter E. Validation of irritable bowel syndrome Global Improvement Scale: an integrated symptom end point for assessing treatment efficacy. Dig Dis Sci 2003;48:1317-1323.

69. Chan AO, Lam KF, Hui WM, et al. Validated questionnaire on diagnosis and symptom severity for functional constipation in the Chinese population. Aliment Pharmacol Ther 2005;22:483-488.

70. Woolery M, Carroll E, Fenn E, et al. A constipation assessment scale for use in pediatric oncology. J Pediatr Oncol Nurs 2006;23: 65-74.

71. Varma MG, Wang JY, Berian JR, Patterson TR, McCrea GL, Hart SL. The constipation severity instrument: a validated measure. Dis Colon Rectum 2008;51:162-172.

72. Wang JY, Hart SL, Lee J, Berian JR, McCrea GL, Varma MG. A valid and reliable measure of constipation-related quality of life. Dis Colon Rectum 2009;52:1434-1442.

73. Bongers ME, Benninga MA, Maurice-Stam H, Grootenhuis MA. Health-related quality of life in young adults with symptoms of constipation continuing from childhood into adulthood. Health Qual Life Outcomes 2009;7:20.

74. Voskuijl WP, van der Zaag-Loonen HJ, Ketel IJ, Grootenhuis MA, Derkx BH, Benninga MA. Health related quality of life in disorders of defecation: the Defecation Disorder List. Arch Dis Child 2004;89:1124-1127.

75. Knowles CH, Eccersley AJ, Scott SM, Walker SM, Reeves B, Lunniss PJ. Linear discriminant analysis of symptoms in patients with chronic constipation: validation of a new scoring system (KESS). Dis Colon Rectum 2000;43:1419-1426.

76. Altomare DF, Spazzafumo L, Rinaldi M, Dodi G, Ghiselli R, Piloni V. Set-up and statistical validation of a new scoring system for obstructed defaecation syndrome. Colorectal Dis 2008;10:84-88.

77. Marquis P, De La Loge C, Dubois D, McDermott A, Chassany O. Development and validation of the Patient Assessment of Constipation Quality of Life questionnaire. Scand J Gastroenterol 2005;40:540-551.

78. Frank L, Kleinman L, Farup C, Taylor L, Miner P Jr. Psychometric validation of a constipation symptom assessment questionnaire. Scand J Gastroenterol 1999;34:870-877. 
79. Downing GM, Kuziemsky C, Lesperance M, Lau F, Syme A. Development and reliability testing of the Victoria Bowel Performance Scale (BPS). J Pain Symptom Manage 2007;34:513-522.

80. Jones R, Coyne K, Wiklund I. The gastro-oesophageal reflux disease impact scale: a patient management tool for primary care. Aliment Pharmacol Ther 2007;25:1451-1459.

81. Liu JY, Woloshin S, Laycock WS, Rothstein RI, Finlayson SR, Schwartz LM. Symptoms and treatment burden of gastroesophageal reflux disease: validating the GERD assessment scales. Arch Intern Med 2004;164:2058-2064.

82. Puhan MA, Guyatt GH, Armstrong D, et al. Validation of a symptom diary for patients with gastro-oesophageal reflux disease. Aliment Pharmacol Ther 2006;23:531-541.

83. Velanovich V. The development of the GERD-HRQL symptom severity instrument. Dis Esophagus 2007;20:130-134.

84. Jones R, Junghard O, Dent J, et al. Development of the GerdQ, a tool for the diagnosis and management of gastro-oesophageal reflux disease in primary care. Aliment Pharmacol Ther 2009;30:10301038.

85. Chan Y, Ching JY, Cheung CM, et al. Development and validation of a disease-specific quality of life questionnaire for gastro-oesophageal reflux disease: the GERD-QOL questionnaire. Aliment Pharmacol Ther 2010;31:452-460.

86. Holtmann G, Chassany O, Devault KR, et al. International validation of a health-related quality of life questionnaire in patients with erosive gastro-oesophageal reflux disease. Aliment Pharmacol Ther 2009;29:615-625.

87. Paré P, Meyer F, Armstrong D, Pyzyk M, Pericak D, Goeree R. Validation of the GSFQ, a self-administered symptom frequency questionnaire for patients with gastroesophageal reflux disease. Can J Gastroenterol 2003;17:307-312.

88. Revicki DA, Wood M, Wiklund I, Crawley J. Reliability and validity of the Gastrointestinal Symptom Rating Scale in patients with gastroesophageal reflux disease. Qual Life Res 1998;7:75-83.

89. Shikiar R, Flood E, Siddique R, Howell J, Dodd SL. Development and validation of the Gastroesophageal Reflux Disease Treatment Satisfaction Questionnaire. Dig Dis Sci 2005;50:2025-2033.

90. Malaty HM, O'Malley KJ, Abudayyeh S, Graham DY, Gilger MA. Multidimensional measure for gastroesophageal reflux disease (MM-GERD) symptoms in children: a population-based study. Acta Paediatr 2008;97:1292-1297.

91. Teixeira JP, Mosquera V, Flores A. Long-term outcomes of quality of life after laparoscopic Nissen fundoplication. Hepatogastroenterology 2009;56:80-84.

92. De La Loge C, Trudeau E, Marquis P, et al. Responsiveness and interpretation of a quality of life questionnaire specific to upper gastrointestinal disorders. Clin Gastroenterol Hepatol 2004;2:778786.

93. Kim J, Keininger DL, Becker S, Crawley JA. Simultaneous development of the Pediatric GERD Caregiver Impact Questionnaire (PGCIQ) in American English and American Spanish. Health Qual Life Outcomes 2005;3:5.

94. Gill SK, Maltepe C, Koren G. The effect of heartburn and acid reflux on the severity of nausea and vomiting of pregnancy. Can J Gastroenterol 2009;23:270-272.

95. Dan D, Seetahal S, Naraynsingh V. Laparoscopic Nissen fundopli- cation for improved gastrointestinal symptoms and quality of life. West Indian Med J 2009;58:8-12.

96. Radajewski R, Hazebroek EJ, Berry H, Leibman S, Smith GS Short-term symptom and quality-of-life comparison between laparoscopic Nissen and Toupet fundoplications. Dis Esophagus 2009; 22:84-88.

97. Zeman Z, Rózsa S, Tihanyi T, Tarkó E. Psychometric documentation of a quality-of-life questionnaire for patients undergoing antireflux surgery (QOLARS). Surg Endosc 2005;19:257261.

98. Shaw MJ, Talley NJ, Beebe TJ, et al. Initial validation of a diagnostic questionnaire for gastroesophageal reflux disease. Am J Gastroenterol 2001;96:52-57.

99. Belafsky PC, Postma GN, Koufman JA. Validity and reliability of the reflux symptom index (RSI). J Voice 2002;16:274-277.

100. Bardhan KD. Look - but also listen! ReQuest: a new dimensionoriented GERD symptom scale. Drugs Today (Barc) 2004;40(suppl A):15-19.

101. Macran S, Wileman S, Barton G, Russell I; REFLUX trial group. The development of a new measure of quality of life in the management of gastro-oesophageal reflux disease: the Reflux questionnaire. Qual Life Res 2007;16:331-343.

102. Coyne KS, Wiklund I, Schmier J, Halling K, Degl' Innocenti A, Revicki D. Development and validation of a disease-specific treatment satisfaction questionnaire for gastro-oesophageal reflux disease. Aliment Pharmacol Ther 2003;18:907-915.

103. Phipps E, Braitman LE, Stites S, Leighton JC. Quality of life and symptom attribution in long-term colon cancer survivors. J Eval Clin Pract 2008;14:254-258.

104. Nakamura M, Kido Y, Yano M, Hosoya Y. Reliability and validity of a new scale to assess postoperative dysfunction after resection of upper gastrointestinal carcinoma. Surg Today 2005;35:535-542.

105. Ikenaga N, Nishihara K, Iwashita T, Suehara N, Mitsuyama S. Long-term quality of life after laparoscopically assisted distal gastrectomy for gastric cancer. J Laparoendosc Adv Tech 2006;16: 119-123.

106. Portenoy RK, Thaler HT, Kornblith AB, et al. The Memorial Symptom Assessment Scale: an instrument for the evaluation of symptom prevalence, characteristics and distress. Eur J Cancer 1994;30A:1326-1336.

107. Dupuis LL, Taddio A, Kerr EN, Kelly A, MacKeigan L. Development and validation of the pediatric nausea assessment tool for use in children receiving antineoplastic agents. Pharmacotherapy 2006;26:1221-1231

108. Tokunaga M, Hiki N, Ohyama S, et al. Effects of reconstruction methods on a patient's quality of life after a proximal gastrectomy: subjective symptoms evaluation using questionnaire survey. Langenbecks Arch Surg 2009;394:637-641.

109. Satoh S, Sato K, Habuchi T, Matsuo S, Sasaki S, Kato T. Healthrelated quality of life of ileocecal rectal bladder compared with ileal conduit diversion: a questionnaire survey. Int J Urol 2002;9:385391; discussion 391.

110. Scarpa M, Barollo M, Polese L, Keighley MR. Quality of life in patients with an ileostomy. Minerva Chir 2004;59:23-29.

111. Smith GD, Watson R, Palmer KR. Inflammatory bowel disease: developing a short disease specific scale to measure health related 
quality of life. Int J Nurs Stud 2002;39:583-590.

112. Martin A, Leone L, Fries W, Naccarato R. Quality of life in inflammatory bowel disease. Ital J Gastroenterol 1995;27:450-454.

113. Loonen HJ, Grootenhuis MA, Last BF, de Haan RJ, Bouquet J, Derkx BH. Measuring quality of life in children with inflammatory bowel disease: the impact-II (NL). Qual Life Res 2002;11:47-56.

114. Walmsley RS, Ayres RC, Pounder RE, Allan RN. A simple clinical colitis activity index. Gut 1998;43:29-32.

115. Griffiths AM, Nicholas D, Smith C, et al. Development of a quality-of-life index for pediatric inflammatory bowel disease: dealing with differences related to age and IBD type. J Pediatr Gastroenterol 1999;28:S46-S52.

116. Turner D, Otley AR, Mack D, et al. Development, validation, and evaluation of a pediatric ulcerative colitis activity index: a prospective multicenter study. Gastroenterology 2007;133:423-432.

117. Irvine EJ, Zhou Q, Thompson AK. The Short Inflammatory Bowel Disease Questionnaire: a quality of life instrument for community physicians managing inflammatory bowel disease. CCRPT Investigators. Canadian Crohn's Relapse Prevention Trial. Am J Gastroenterol 1996;91:1571-1578.

118. Guassora AD, Kruuse C, Thomsen OO, Binder V. Quality of life study in a regional group of patients with Crohn disease. A structured interview study. Scan J Gastroenterol 2000;35:1068-1074.

119. Coyne K, Joshua-Gotlib S, Kimel M, Thompson C, Lewis A, Danilewitz M. Validation of the treatment satisfaction questionnaire for Crohn's disease (TSQ-C). Dig Dis Sci 2005;50:252-258.

120. Lacasse A, Bérard A. Validation of the nausea and vomiting of pregnancy specific health related quality of life questionnaire. Health Qual Life Outcomes 2008;6:32.

121. Koren G, Boskovic R, Hard M, Maltepe C, Navioz Y, Einarson A. Motherisk-PUQE (pregnancy-unique quantification of emesis and nausea) scoring system for nausea and vomiting of pregnancy. Am J Obstet Gynecol 2002;186(suppl 2):S228-S231.

122. Magee LA, Chandra K, Mazzotta P, Stewart D, Koren G, Guyatt GH. Development of a health-related quality of life instrument for nausea and vomiting of pregnancy. Am J Obstet Gynecol 2002;186 (suppl 2):S232-S238.

123. Khanna D, Hays RD, Park GS, et al. Development of a preliminary scleroderma gastrointestinal tract 1.0 quality of life instrument. Arthritis Rheum 2007;57:1280-1286.

124. Brunner HI, Johnson AL, Barron AC, et al. Gastrointestinal symptoms and their association with health-related quality of life of children with juvenile rheumatoid arthritis: validation of a gastrointestinal symptom questionnaire. J Clin Rheumatol 2005;11:194-
204.

125. Caplan A, Walker L, Rasquin A. Development and preliminary validation of the questionnaire on pediatric gastrointestinal symptoms to assess functional gastrointestinal disorders in children and adolescents. J Pediatr Gastroenterol Nutr 2005;41:296-304.

126. Hiller L, Radley S, Mann CH, et al. Development and validation of a questionnaire for the assessment of bowel and lower urinary tract symptoms in women. BJOG 2002;109:413-423.

127. Markland AD, Richter HE, Burgio KL, Wheeler TL 2nd, Redden DT, Goode PS. Outcomes of combination treatment of fecal incontinence in women. Am J Obstet Gynecol 2008;199:699.e1-e7.

128. Bijkerk CJ, de Wit NJ, Muris JW, Jones RH, Knottnerus JA, Hoes AW. Outcome measures in irritable bowel syndrome: comparison of psychometric and methodological characteristics. Am J Gastroenterol 2003;98:122-127.

129. Waldstein SR, Neumann SA, Drossman DA, Novack DH. Teaching psychosomatic (biopsychosocial) medicine in United States medical schools: survey findings. Psychosom Med 2001;63: 335-343.

130. Cook KF, O'Malley KJ, Roddey TS. Dynamic assessment of health outcomes: time to let the CAT out of the bag? Health Serv Res 2005;40(5 Pt 2):1694-1711.

131. Chakravarty EF, Bjorner JB, Fries JF. Improving patient reported outcomes using item response theory and computerized adaptive testing. J Rheumatol 2007;34:1426-1431.

132. Greenhalgh J, Long AF, Flynn R. The use of patient reported outcome measures in routine clinical practice: lack of impact or lack of theory? Soc Sci Med 2005;60:833-843.

133. Valderas JM, Kotzeva A, Espallargues M, et al. The impact of measuring patient-reported outcomes in clinical practice: a systematic review of the literature. Qual Life Res 2008;17:179-193.

134. Greenhalgh J. The applications of PROs in clinical practice: what are they, do they work, and why? Qual Life Res 2009;18:115-123.

135. Lohr KN, Zebrack BJ. Using patient-reported outcomes in clinical practice: challenges and opportunities. Qual Life Res 2009;18:99107.

136. Rose M, Bezjak A. Logistics of collecting patient-reported outcomes (PROs) in clinical practice: an overview and practical examples. Qual Life Res 2009;18:125-136.

137. Spiegel BM, Bolus R, Agarwal N, et al. Measuring symptoms in the irritable bowel syndrome: development of a framework for clinical trials. Aliment Pharmacol Ther 2010;32:1275-1291.

138. Shaw RJ, Ferranti J. Patient-provider internet portals - patient outcomes and use. Comput Inform Nurs 2011;29:714-718. 